\title{
The need of a win-win regulation regarding the harmonization of advantages for the renewable energy sector and the concerns about the environment
}

\section{Dan MORARU}

\author{
Bucharest University of Economic Studies, Bucharest, Romania
}

\begin{abstract}
The main theme of this paper is the evolution of theories and suppositions regarding environment and growth. The sustainable green growth and the sustainable green capitalism concepts have attracted the interest and imagination of policy makers and industry, and also stimulated many exciting new ideas and practical actions such as the "triple bottom line" which refers to harmonizing and balancing out the three interests that are linked with sustainable business: economic, environmental and social ones. The policy has to create a workable association between what the government can ensure and not tax and what it cannot ensure and must tax. In this manner we get a win-win regulation meaning that both sides win. National and supranational policies are part of the macro-level governance and very relevant for the sustainable development of the EU Member States and for the stability of the EU itself.
\end{abstract}

Keywords: win-win regulation, sustainable green capitalism, macro-level of governance, renewable energy, environment, green growth.

Please cite this article as following: Moraru, D. (2015), "The need for a win-win regulations regarding the harmonization of advantages for the renewable energy sector and the concerns about the environment", Management \& Marketing. Challenges for the Knowledge Society, Vol. 10, No. 1, pp. 61-71, DOI: 10.1515/mmcks-2015-0005.

\section{Introduction}

By making the most of the environmental crisis, the global economy has been able to fruitfully exploit the opportunities for transformation and renewal that were provided, in order to ensure a more appropriate "Green Growth Future". We should be able to see by now how each of the opportunities was developed into concepts at each level of the administration. That which drives the Green Growth at this particularly level is the interest of increasing competitiveness. At all levels, from national to European and global, competitiveness is seen and highly recommended as a growth formula and so managers and governors are harmonizing both national and supranational interests. A way to define a country's competitiveness is by the ability to produce services and goods that are in conformity with the requirements of international markets and at the same time and are able to sustain or expand the cash flow. Some are viewing the development of rigid environment regulations to be a way of improving competiveness at a national level. As a way to fight against recession, the OECD (2012) and UNEP (2010) gave strong recommendations for promoting stimulus packages that were accepted and implemented by the governments in different ways in order to expand the green energy production, and also the sector of environmental services and goods.

Correspondence: Moraru Dan dan.moraru33@ gmail.com 


\section{From weak to strong eco-modernization - a win-win regulated MMCKS industrial metabolism}

The Green Growth (GG) has a significant impact on the environment as well as on the economy. In addition, GG is completely changing not only the way in which energy is produced, but also the way in which energy is dispatched, forecasted, traded and rewarded. This type of energy growth must be funded and implemented through economic approaches which involve in the process multi-scale governance arrangements and multi-stakeholders. Rather than separating the complex relation between humans and environment, policies and managerial mechanisms are set into motion to advocate synergies among environment and growth.

This evolution is being closely followed from "zero growth" leading up to sustainability and facing the issue of uncontrolled growth and other coexisting theories that accentuate the founding base for ecological modernization that leads to a path for all participants where they can profit and freely coexist.

We consider important the examination of emerging approaches on GG and how this approach has shifted over the past decades, where it has been, how it has evolved over time and who its predecessors were. In order to do so, GG must be defined and measured, and in this respect the quantity of green energy produced and consumed in an economy is the most significant parameter along with the mechanisms and the sustainability models implemented by the government as a response to environmental challenges. The concept of green sustainable development has to be defined and connected to all ways and models helping to meet today needs but without putting at risk the chances and the full right of the next generations to find their own way to meet their needs. This concept has captured the interest and imagination of some policy makers and industries and also stimulated many exciting new ideas and actions.

The purpose of all of these policies is to prioritize a need for a de-centered regulation which would imply community rules, industry standards and voluntary agreements, as a change from top down government led regulation. Such kind of decentered regulation is far away from being implemented in Romania, but according to the administrative design of the country in eight regions, the de-centralization process will act as a trigger for green sustainable development.

It is through a combined effort at the European level, the civil society and an alliance among companies, that sustainable economic growth is to be achieved, and at the same time providing environmental protection in the pursuit of technological development, reducing social injustice like poverty and inequality trough economic and institutional programs. It is hard to tell how all of these ideas of GG can be applied in the economic system and how policies could provide all the requirements of generations to come, although the implications of these ideas are more difficult to implement, they look good on paper but the implications are perhaps not totally pertinent to the reality of GG. The effort of translating sustainable GG idea into policies was undertaken during the 1990s, it was the first vocalization of such an idea, of how sustainable green capitalism could function relying on the implementation of such policies. Directly connected to the concept of sustainable green capitalism, ecological economics is a new branch of economics that emerged in order to face the complexity of the economic systems involved, including also other systems such as social and 
biological which are interconnected. In spite of all these connections among ecological systems, the idea of ecological economics is dismissed not only by the majority of mainstream Romanian environmental economic policy makers, but also it gains with difficulty a higher profile in the curricula of Romanian academic educational programs. The transfer of property over the national oil and gas reserves, the irresponsible depletion of forests combined with the search for some adventurous solutions of extracting shale gas by hydraulic fracturing are only a few bad examples regarding the commitment of Romanian decision makers for ecological economics and sustainable green growth.

Jacobs (1991) cited in Gardner (2011) uses the term "orthodox" to describe how these ideas are being altered. This "orthodox" concept refers to how environmental economics works, using the neoclassical theory to shape the studies of environmental problems. Environmental goods and services are viewed in the neoclassical environmental economics as mere commodities, where the process of supply and demand is ruled by the economic factors of the free market which in turn affect the price of commodities. Commodities such as drinkable water and clean air are free commodities that are being drained and exhausted because their demand on the market is not restricted by price, and so this ends up being the main cause of environmental pollution and contamination. In the matter of how to ensure the translating sustainability into practice, it all comes down to creating more procedure plans to assign for these types of environmental goods and services a current and future price or a material worth.

In the business area things look differently. Managerial practices seemed to have found a way to incorporate these ideas and bring forward a new outcome in which for both - economy and environment - there is a possibility of gain. This has been defined as a win-win situation. Researchers and policy makers along with the aid of international organizations such as United Nations (UN), World Bank (WB) and World Trade Organization (WTO) attempt to address the issue of translating sustainability into practice, and thus try to figure out a way to employ the potential of markets to boost environmental protection. This strategy would require an intricate combination of policy mechanisms such as environmental taxes, regulation and government expenditure, subsidies and voluntary agreements. Addressing the issues of sustainability and green policy tends to become a major concern in the policy and management departments (Volkmann and Gruenhagen, 2010).

Sustainability found its way into managerial practice and was incorporated into it through eco-modernization at the corporate level. What corporate management strategies need is to accept this as a requirement for the issue of environmental integration with management practices. The World Business Council for Sustainable Development (WBCSD) expressed publically the key benefits for businesses which decide to go sustainable. These benefits are situated in the economic area, but in order to solve the environmental problems that concurred, there's only one practical course of action. It is called the "triple bottom line" and it refers to harmonizing and balancing out the three interests that are linked with sustainable business: economic, environmental and social ones.

Jänicke (2008), cited in Frondel et al. (2009) noticed the significance of the intervention of the government which was necessary to start the changes that the 
green market economy required, and also pointed that if the intervention is conform to a specific scheme, it does not pose a threat to companies and their business interests. On the other hand, the neo-institutional theory implies that environmental management is nothing more than a replication of organizational practices as a response to the political impact, such as government strains or standard collective responses when facing the uncertainty related to environmental problems. Companies deal with environmental laws in two ways, the first one is to have a passive response to them, and the second one is to seek out competitive benefits that may arise from situations such as these. In reality, the sustainability that is promoted by ecomodernization has a wider span of action which is composed of ever more expanding strategies ranging from weak to strong conceptions in regard to the liability of efficiency. The weak eco-modernization has an economic and technical aim of improving the production in a more environmentally efficient way, through management that requires innovation and the care for the environment, and so increasing the profit while the environmental costs decrease. The technological innovation is being supported by eco-efficiency in order to develop more efficient industrial processes, and so reducing emissions and creating a life cycle for a product which decreases the use of resources. All of these factors mixed with the use of economic mechanisms such as permits, tolls and taxes succeed in internalizing and reducing environmental costs.

Poverty and social vulnerability are two important social issues that are ignored in this perspective in most of the cases. Strong eco-modernization is the opposite of weak eco-modernization and looks not just to lower as much as possible the occurrence of risks, but also to anticipate and avoid the arbitrary risks of externalization in space and time. This type of eco-modernization brings to attention the social and political aspects associated with the environmental struggle.

Strong eco-modernization sees the world as a system, a socio-biological one, in which the resources and pollution among poor and rich regions and countries are as geographical flows. There is an injustice in the distribution of resources and pollution with poor and rich areas, there is a tendency for resources to migrate from poorer areas to richer ones; and the tendency for pollution is to flow in the opposite way, from richer to poorer areas (Mordue, 1999). All of these require the implementation of different political and economic systems than the ones that operate at present, in order to encourage a more just geographical and social dispersion of both resources and pollution recipients and producers alike. Corporate strategies tend to relate to strong eco-modernization ideas but pay less attention to the injustice of the distribution of resources and pollution. On the other hand, these ideas place their main emphasis on the environment management strategies that transform the industrial production and are beginning to use the world as a model to recreate a sustainable environmentally industrial process which views the flow of both resources and energies among industries as a natural interaction. These eco-strategies are made up of the following mechanisms "Cradle to cradle" (McDonoungh and Braungart, 2010), "Industrial Ecology", "Biosphere Rules" (Unruh 2008). These include many methods by which to obtain the sustainability of such a strong ecomodernization, like industrial metabolism in which the waste of an industry is recycled or used by another one (Bernstein et al., 2003). 
Cradle to Cradle (McDonoungh and Braungart, 2010) product design supports the idea of the principles of eco-effectiveness and sufficiency in the detriment of waste minimizing and eco-efficiency. This design is based on the same grounds as GG, and tries not to repair the damage that has already been done but try to minimize the impact. This kind of concept is widely spread in some parts of the globe.

Proactive companies are slowly, but surely starting to accept strong ecomodernization strategies, and thus assuming corporate sustainability. In spite of the fact that environmental sustainability has become a more prominent figure in both political and public sector, there is still a gap that remains to be covered between discourse and practice. As to western sustainability issues, there is no real progress toward GG initiatives, but there are some remarkable exceptions. The main goal of sustainable development is to merge and mix social, economic and environmental growth into actual policy objectives, although this has proven to be harder than it seemed. Economic policies are focused on a primary objective, that of economic growth. The previews and actual model of production and consumption were not able to change for a long period of time because there was too little political commitment. Over the last decades, the major catalyst that boosts the governance of environmental concerns in the European Union is thought to be as a race to the top among two identical concepts, which are consumer oversight and regulatory and industry standards. Still they have not been able to produce a significant effect on the uprising of the climate change threats (Howard, 2012).

Many consider that Green Capitalism cannot be reached only with a change in the existing system because the western system is considered to be a materialist one, and such a small change will not be offered from inside the system seeing that any specific solutions only generate new issues in the rush for more and more profit.

The political class became interested in the mater that the green energy can evolve to a successful energy source. The idea that what is green has a remarkable and natural growth can be applied to the energy industry, too but this idea has come at a bad time, considering the global crisis. Even if it is a bad period for the development of green energy, it is a necessity and a cure for the global warming which is a diagnosed and treatable problem. Another reason why there is a need for change is that the actual source of energy is going to collapse sooner or later. It is a great opportunity for the political class to gain confidence from the population with this innovative plan which will strike in both economic and political matters. Several countries like Germany, France, Denmark and others from Asia have promoted this idea. Although, there is to be mentioned a couple of differences between the countries of Asia and Europe. East Asia supports a low carbon sustainable economy, environmentally friendly and with a major impact on society. Europe has adopted and promoted the Green Economy slogan for promoting similar theories. Both ideas are sustained by the Organization of Economic Cooperation and Development (OECD, 2012) and the UN over the dissertation about Green New Deal/Green Growth in relation to a new model of perfect fusion between the energy industry and saving the environment. For a sustainable development of Green Energy the members in question have to be provided with energy markets, a way of developing the natural capital, organize ecofriendly productions, exploit the natural resources for better improvement and enhance the future energy method. Although it is believed that the ecological matter is 
behind the promotion of Green Energy, in fact the economic aspect is the main reason. GG is designed to revive the global economy by making use of natural resources, reduce fuel use, forcing the entire world industry to change into an eco-friendly process. Different states are negotiating the term of GG: EU countries, Japan, and surprisingly some countries which are evolving and strive to start up with a new and innovative project. The discussion is held around the problem that GG is not likely to be an economic success. So, the political class wants to make Green Energy a win-win process. The OECD (2012) has a strategy that will make green energy a sustainable business. They are suggesting to the political class to adjust the legal conditions above the Green Energy so it can be supported both in resources and sources. An idea is that the policy has to create a functional association between what the government can ensure and not tax, and what it cannot ensure and must tax. This way it is a win-win regulation, both sides win. So the government has to ensure the development of green energy technologies, infrastructure, pay the ecological taxes, discharge of the non-ecofriendly investments that are presently made. For those who want to begin an energy business based on green energy the government will provide the technical support, market development, training classes, voluntary labor, they will benefit of experts in the field of green energy, and will benefit of good practices and best advice about where to invest, what natural resources to explore and how to make all of these an eco-friendly industry. According to OECD (2012), the most important thing in developing the GG is perfect laws and regulation of how to create green energy, and, of course, absolute control, support and attention. Also they have a great structured plan, many of the policies are still utopian so most of the governors are skeptical. GG needs a lot of attention nationally and internationally, at all kinds of levels so it can become the greatest and most profitable source of energy ever. The ministers of environment of the EU countries are interested to develop green energy and must gather and establish laws, agreements, and treaties in order to implement a harmonized policy over the entire territory of the Union.

Only when both the leveraging potential and the flexibility of commitment are strong, can the green success be obtained (Rugman and Verbeke, 1998). GG is viewed as an active and changing national strategy that requires the use of environmental regulation to power the market in terms of technology development and creation. GG is addressed especially to companies that function in countries that have poor regulatory systems. If the investment in environmental innovation occurs in the period in which environmental regulation is still weak in order to benefit from the green success, one can discover that although occupying a leadership position, the environmental austerity will increase (Fay and Golomb, 2002).

\section{The term which is used to describe the glue that keeps society together is referred to as social cohesion}

Economic success can be predicted by two factors, the high economic cohesion and the social capital. It is strongly believed that sustainable economic policy and sustainable green growth must specifically try to strengthen social cohesion. In the absence of strong social cohesion, society becomes exposed at the risk of conflicts that impede the ability to work together and share a common vision. Furthermore it is the just and equitable policies that help develop social cohesion, it is a required structure 
MMCKS that guarantees success in the game changing policies that untimely lead to the alignment of power among social groups. In this respect, a renewable energy program has to stimulate the investments in such technologies and the energy consumers have to be actively involved in this energy consumption. For instance, if the railways will paint their trains in green and clearly advertise that they are using green power, by using their services we are investing in green energy, in green growth, and, also, in economic cohesion by sharing a common vision. For the Romanian government it is advisable to implement a development strategy based on social cohesion and to target economic growth and a significant decrease of inequality. GG should focus more on increasing sustainability and advocating for social inclusion.

The Romanian government has to know that the most important concept that brings together regulations, voluntary agreements, multi stakeholders and green consumption is the issue of trust. And in this respect the government must act accordingly. A well planned democracy is the way in which the governance of multi stakeholders can be conceptualized in an effective manner. By using all the communication means that are available such as the reasoning of issues, the dialog in order to support a shared understanding of things it is possible to provide a common decision making by employing the best real democratic decisions, and thus managing to mirror the vast range of interests and minimizing strategizing or money or the interfering of political power. Using solely strategic action is not enough to attain the aim of game changing policies, this only puts forward social resistance and turmoil as expected risks.

\section{Stranded capital}

The transition from the traditional form of energy to more environmental friendly energy systems comes with some risks along the way. One of the risks is that of the sunken capital that is in danger of being abandoned and, thus, turning into a risk for the transition. For the government it is vital to frontally approach a problem of political economy, as the stranded capital in renewable energy projects. In that respect, some specific measures are necessary and strongly recommended: (a) establishing a set of standards for more malleable options, and one example is the adaptation, at a more recent stage, of the carbon capture ready fossil fuel plants; (b) performing an accurate evaluation of forthcoming community requirements, searching for an expansion in the alternative low cost energy options and in options that do not require large intakes of capital; (c) in order to encourage and sustain the alternative energy solutions, there has to be a regulation in the carbon price or a proxy, this would create a well determined anticipation of the fluctuations over time and, thus, providing a powerful catalyst; (d) an administrative framework that oversees the transition, and by doing so it is able to provide a complete view with well determined markers, and so it presents trustworthiness signals and therefore it manages to reduce doubt and it helps on building up credibility (Van Den Bergh, 2008).

\section{Distribution effects}

It is strongly believed that restructuring the energy sector has no or almost no resultant employment changes and it offers a far-ranging balance effects all over the economy and among countries. In this whole process there will be both situations in 
which some parties will gain and some parties will lose, it is the policy makers' job to make sure that the adaptation process is carried out in such a way that it does not interfere with the demands of proper social policies. This kind of policies includes: (a) it is important to have well outlined skills policies and labor market entity. This will make the labor market be more active and go more across the board. A significant part in all of this is the educational policy that helps in encouraging and in the training workers in order to them from contacting or moving towards much larger firms and industries; (b) another policy includes the support of consumption and demand power in markets, and most of the programmers that try and spread out the renewable and reliable energy which is also safe and efficient, to the other sectors of society that cannot afford them; (c) in order to make the transition from traditional energy subsidies that have dangerous side effects on the environment to the new era of policies aimed at helping the poorer sector of the society, first of all we must keep in mind how to compensate this impact on less developed communities. All of this will eventually lead to awareness in consumer behavior, meaning that they will use the energy that the government provides, in a more efficient way (UNEP, 2010).

Energy and the technologies used to produce energy have a direct and also an indirect effect on both environment and humans. The direct impacts of energy process are reflected in the air, water and land. And the indirect outcomes of producing energy appear as a result of polluting the air, water and soil. The indirect outcomes are on humans and their health, food security and ecosystems; they can be seen as a series of different resulting connections between the first direct impacts and the various types of environments they come in contact with. They are all interconnected, and once one of them has been polluted or compromised, the phenomenon can easily spread to all there is in its vicinity and sometimes it can even spread beyond that.

The prices of the fossil fuels sky rocketed with the 2008 economic crisis, and the following long recession. Right now, the prices are decreasing as an effect of the political confrontation between Russia and the Euro-Atlantic states and this is very useful for understanding that the price is not only the result that lies at the intersection of supply and demand. Therefore, the geopolitical events are the cause for this rise and fall in the fossil fuel prices. The fluctuations of fossil fuel prices lead to threats on the economic activity, and they can put the world's natural capital at medium and long term risks. Enhancing global security on the matter of clean energy requires an energy mechanism to ensure the security of green energy, allowing the economy to grow by empowering it with responsible environmental conservation and protection of resources.

\section{Conclusions at the national level of Romania}

The national authority responsible for regulating energy must be an independent institution concerned about the harmonization of the triangle of interests represented by the: State - Energy Producers (power plants) - Energy Consumers (industries, households, municipalities etc.). Romania is a specific example because of its electricity production manly coming from power plants remained under state control and still has not been privatised. From this perspective, the independent and neutral position of the Regulatory Authority for Energy (ANRE) was stressed by the state and 
moved from its normal position - in the centre of the triangle described in Figure 1 - in the direction of the state and power producers' peaks (see Figure 2).

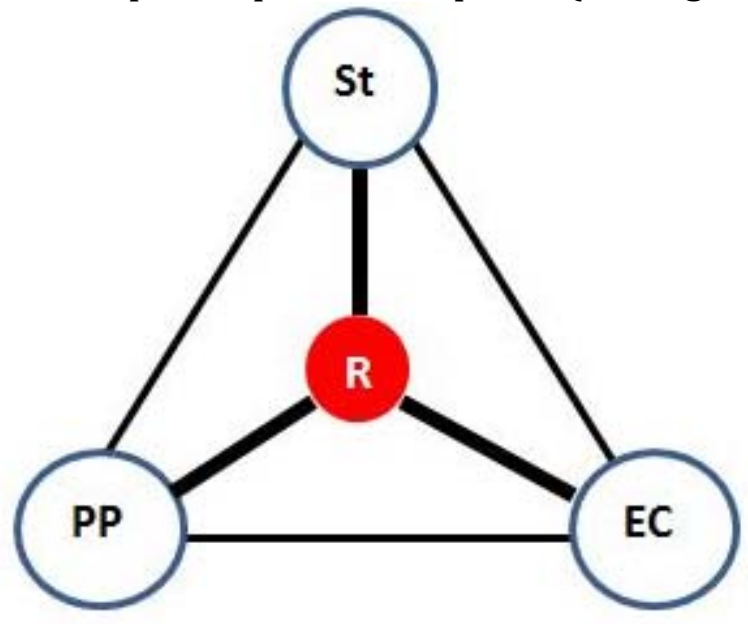

Figure 1: Normal/Ideal position of the regulatory body

Source: Author's own contribution.

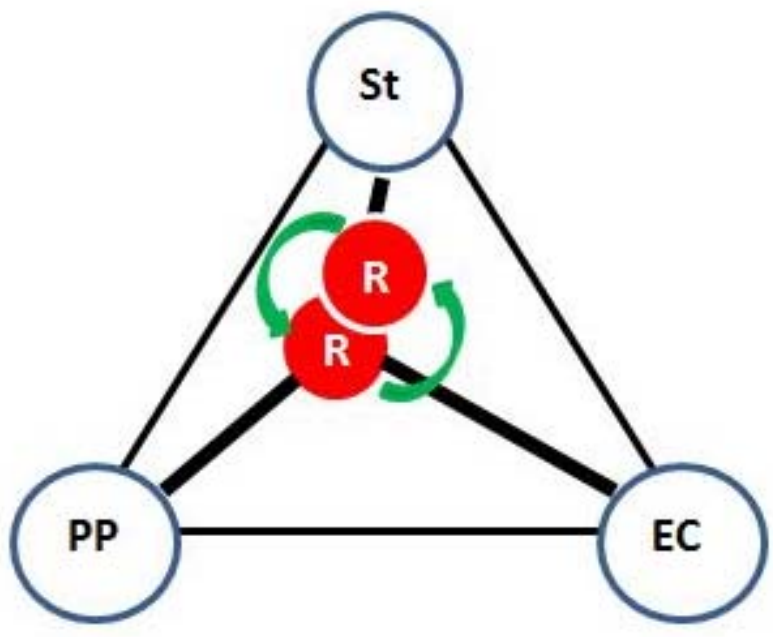

Figure 2: Eccentric/Deflected position of the regulatory body (Where: St = State; $\mathrm{PP}=$ Power Plants (Energy Producers); $\mathrm{EC}=$ Energy Consumers; $\mathrm{R}=$ Regulator Body) Source: Author's own contribution.

Since its establishment in 2000 and after a short period of neutral independence, the Romanian regulatory body has been subordinated by Government Ordinances to the Ministry of Economy, to the Parliament or to the General Secretariat of the Government. This continuous interventions affected the neutrality and the equidistance of the regulatory body and more important its activity in favour of power plants and the state itself by legal dispositions regarding the prices for electricity transportation, distribution and taxation, disadvantaging the householders, industrial consumers and municipalities. This kind of state intervention had dramatic financial 
consequences for it created legal financial flows from the accounts of energy consumers in the accounts of the energy producers and the state and this was a sad shift from an initial „win-win regulation” to a kind of „win-lose regulation”. Such slippages are also observable in Germany and in other EU countries, but they are not so obviously in favour of some or other actors of the electricity market and when they are disturbing the market and affecting the social equilibrium, the Government takes decisions for implementing the necessary corrections and thus avoiding further distortions. In this respect, an equidistant regulation contributes to harmonizing the interests of all participants in the electricity market and can be described as a "winwin regulation" and a trigger for sustainable development.

Antagonistically, a regulatory body captive of a pool of market interests will issue secondary legislation in favour of this power pool, which will disadvantage other market participants, will violate its own reason of existence, will distort the market by generating effects difficult to correct and with high costs. This kind of regulation can be described as "win-lose regulation" and it must be avoided.

Romania over-stimulated the investments in green energy and subsequently dramatically restricted these incentives assuming the criticism of investors regarding its unpredictability, inconsistency regarding the renewable energy sector. In order to understand why some EU states have a less developed renewable energy sector than others, we have to go further and reveal the complicated mixture of political decisions, international lobbying and objective economic constraints and to stimulate also the free thoughts and the research of the economic growth and the environment.

Is there a link between the regulation of energy as a component of macro-level governance and the economic growth of the economy and its GDP? The answer is yes, and this is a very sensitive connection which may affect the sustainable development of the country.

The humble contribution of the author was to emphasize and highlight the differences between two kinds of regulations (win-win regulations and win-lose regulations - see the Figure 1 and 2) and to notice their very relevant roles as triggers for the sustainable development of the companies and the general economy in the green capitalism framework. The need of an independent regulation system in the energy sector is determined by the need of harmonization of all the interests and avoidance of financial resources inequality which leads to great differences in the negotiation power, to erosion of constitutional interests of the disadvantaged people, companies, municipalities and other bodies.

\section{References}

Bernstein, M., Fonkych, K., Loeb, S. and Loughran, D. (2003), State Level Changes in Energy Intensity and Their National Implications, Rand Corporation, Massachusetts.

Frondel, M. et al. (2009), "Economic impacts from the promotion of renewable energy technologies: the German experience”, Ruhr Economic Papers, No. 156.

Fay, J. and Golomb, D. (2002), Energy and the environment, Oxford University Press, Oxford.

Gardner, R. (2011), Energy: Green Science Projects About Solar, Wind, and Water Power, Enslow Publishers, Berkeley Heights. 
MMCKS Howard, S. (2012), Energy Managemen,. M-Y Books Distribution.

House of Lords, Science and Technology Committee (2005-2006), Renewable Energy: Practicalities, and Energy Efficiency: Government Responses Report, The Stationery Office, London.

House of Commons (2006), Department of Trade and Industry: Renewable energy, Sixth Report of Session 2005-06, The Stationary Office Limited, London.

Mordue, J. (1999), Energy demand and planning, Routledge, London.

OECD (2012), "Green Growth Studies Energy", International Energy Agency, available online at: www.oecd.org/dataoecd/37/42/49157219.pdf (accessed February 18, 2015).

Rugman, A.M. and Verbeke, A. (1998), "Corporate Strategies and Environmental Regulations", Strategic Management Journal, Vol. 19, No. 1, pp. 363-375.

Unruh, G. (2008), "Biosphere Rules", available online at: hbr.org/2008/02/thebiosphere-rules/ar/1 (accessed February 10, 2015).

United Nations Environment Programme and New Energy Finance (UNEP), (2010), "Global Trends in Sustainable Energy Investment 2010: Analysis of Trends and Issues in the Financing of Renewable Energy and Energy Efficiency", available online at: www.unep.org/pdf/Global_trends_report_2009.pdf (accessed, Frbruary 12, 2015)

van den Bergh, J.C.J.M. and Bruinsma, F. (2008), Managing The Transition To Renewable Energy, Edward Elgar Publishing, Massachussetts.

Volkmann, C. and Gruenhagen, M. (2010), Entrepreneurship in a European Perspective, Springer Gabler Plus, Heidelberg. 